\title{
Renal Adaptation to Potassium in the Adrenalectomized Rabbit

\author{
Role of Distal Tubular Sodium-Potassium Adenosine Triphosphatase
}

\author{
Lal C. Garg and Neelam Narang \\ Department of Pharmacology and Therapeutics, University of Florida College of Medicine, Gainesville, Florida 32610
}

\begin{abstract}
Potassium secretion and sodium-potassium adenosine triphosphatase (Na-K-ATPase) activity in the distal nephron segments are known to be influenced by the dietary intake of $\mathrm{K}^{+}$. This has been attributed to a change in the plasma aldosterone level, which also influences $\mathrm{K}^{+}$secretion and Na-K-ATPase activity in the distal nephron. To investigate whether or not dietary $\mathrm{K}^{+}$can modulate Na-K-ATPase activity in the distal nephron independently of aldosterone, we determined $\mathrm{Na}-\mathrm{K}$-ATPase activity in four distinct nephron segments of adrenalectomized (adx) rabbits given four specific diets for 1 wk before experimentation. $\mathrm{Na}$ K-ATPase activity was determined by a fluorometric microassay in which ATP hydrolysis is coupled to NADH oxidation. The nephron segments examined were the distal convoluted tubule (DCT), the connecting tubule (CNT), the cortical collecting duct (CCD), and the outer medullary collecting duct (MCD). All diets were similar in composition except for their $\mathrm{K}^{+}$contents, which were $100,300,500$, and $700 \mathrm{meq} / \mathrm{kg}$ in groups $1-4$, respectively. In these adx animals, Na-K-ATPase activity increased $>200 \%$ in the $\mathrm{CCD}$ as the dietary intake of $\mathrm{K}^{+}$increased. There was a linear relationship between $\mathrm{K}^{+}$excretion and the enzyme activity in this segment. There was a $50 \%$ increase in Na-K-ATPase activity in the CNT as the dietary intake of $\mathrm{K}^{+}$increased in adx animals. However, there were no significant differences in $\mathrm{Na}-$ K-ATPase activities in the DCT and MCD among the four treatment groups. It is concluded that dietary $\mathrm{K}^{+}$intake can influence Na-K-ATPase activity in the CCD and CNT independently of plasma aldosterone levels.

\section{Introduction}

It has been shown that renal sodium-potassium adenosine triphosphatase (Na-K-ATPase) ${ }^{1}$ activity increases when potassium $\left(\mathrm{K}^{+}\right)$intake is increased in animals (1). This finding has been regarded as an adaptive mechanism whereby the kidney can excrete more $\mathrm{K}^{+}$. Because $\mathrm{K}^{+}$secretion occurs in the late distal tubule and the collecting duct $(2,3)$, the changes in Na-K-ATPase activity in these nephron segments probably play a major role in $\mathrm{K}^{+}$adaptation $(4,5)$. The mineralocorticoids such as aldo-

Address reprint requests to Dr. Garg, Box J-267 JHMHC, University of Florida College of Medicine, Gainesville, FL 32610. 1985.

Received for publication 30 July 1984 and in revised form 13 May

1. Abbreviations used in this paper: adx, adrenalectomized; ATPase, adenosine triphosphatase; $\mathrm{CCD}$, cortical collecting duct; $\mathrm{CNT}$, connecting tubule; DCT, distal convoluted tubule; MCD, medullary collecting duct.

J. Clin. Invest.

(c) The American Society for Clinical Investigation, Inc.

0021-9738/85/09/1065/06 \$1.00

Volume 76, September 1985, 1065-1070 sterone have also been shown to increase Na-K-ATPase activity selectively in the late distal tubule and the collecting duct (6). Because an increase in plasma $\mathrm{K}^{+}$increases aldosterone secretion $(7,8)$, it has not been established whether the renal adaptation to $\mathrm{K}^{+}$can occur independently of mineralocorticoids. Therefore, we studied the effect of dietary $\mathrm{K}^{+}$intake on Na-K-ATPase activity in the distal nephron of adrenalectomized ( $\mathrm{adx})$ rabbits.

\section{Methods}

Animals. Male rabbits weighing 1,000-1,500 g were adrenalectomized bilaterally and divided into four groups. The completeness of adrenalectomy was assessed by the absence of aldosterone in the plasma. All animals were given $0.12 \mathrm{M} \mathrm{NaCl}$ to drink and were fed specially formulated diets (Teklad, Madison, WI) for 7-12 d before experimentation. Animals in group 1 received a basic diet ${ }^{2}$ that contained $100 \mathrm{meq} / \mathrm{kg}$ of potassium. Groups 2, 3, and 4 received diets that contained an increased quantity of potassium (Table I) and a slightly decreased quantity of sucrose and cornstarch. The $\mathrm{K}^{+}$content of the group 2 diet was equivalent to that of normal rabbit laboratory diet $(300 \mathrm{meq} / \mathrm{kg})$, but was higher than that of normal rat laboratory diet $(200 \mathrm{meq} / \mathrm{kg})(9)$. To estimate the amount of food ingested, the diet given to each animal was monitored over the entire period of experimentation.

Collection and analysis of urine and plasma. The methods followed for collection and analysis of urine and plasma were the same as described previously (6). A 48-h urine specimen was collected by placing each animal in a metabolic cage before experimentation. Blood was collected from the neck stump after decapitation. $\mathrm{Na}^{+}$and $\mathrm{K}^{+}$content in the plasma and urine were determined by flame photometry (model 143, Instrumentation Laboratory, Inc., Lexington, MA), and plasma aldosterone was determined by radioimmunoassay (Hazelton Laboratories, Vienna, VA). Plasma and the urine creatinine levels were determined by the Jaffe reaction (10).

Microdissection of nephron segments. The methods for microdissection and preparation of nephron segments have been described in detail previously (6). In summary, the rabbits were decapitated and one kidney was excised and perfused with collagenase solution. Tangential slices and medullary rays of the perfused kidney were incubated in collagenase solution with $100 \% \mathrm{O}_{2}$ at $37^{\circ} \mathrm{C}$ for $30-50 \mathrm{~min}$. The tissue was then transferred to cold $\left(4^{\circ} \mathrm{C}\right)$ buffer without collagenase and the individual nephron segments were dissected under a stereomicroscope. The segments were identified by their morphologic characteristics and location in the renal tissue. Two types of segments were dissected out from the superficial nephrons in the tangential slice: the distal convoluted tubule (DCT) and the connecting tubule (CNT). Two additional nephron segments were dissected from the medullary rays: the cortical collecting duct (CCD) starting from the junction of two tubules (DCT) and the medullary collecting duct (MCD) from the inner stripe of the outer medulla. Six tubules of each type were dissected from each rabbit to determine ATPase activities in triplicate (three with and three without ouabain).

Determination of Na-K-ATPase activity in individual nephron segments. Na-K-ATPase activity was determined in the intact nephron segments by a microassay described in detail previously (6). In summary,

2. Composition of the basic diet: Sucrose $18.1 \%$, cornstarch $18.0 \%$, highprotein casein and other amino acids $17.7 \%$, dextrose $15.0 \%$, cellulose fiber $15.0 \%$, dehydrated alfalfa meal $6.0 \%$, corn oil $5 \%$, vitamin mix $1.2 \%, \mathrm{NaCl} 1.11 \%, \mathrm{KCl} 0.39 \%$, and other minerals $2.5 \%$. 
Table I. Potassium Content, Food Intake, Body Weight, and Kidney Weight of Experimental Rabbits

\begin{tabular}{|c|c|c|c|c|c|c|}
\hline $\begin{array}{l}\text { Experimental } \\
\text { group }\end{array}$ & Dietary $\mathrm{K}^{+}$content & Food intake & $\mathrm{K}^{+}$intake & Body weight & $\begin{array}{l}\text { Kidney } \\
\text { weight }\end{array}$ & $\begin{array}{l}\text { Survival after } \\
\text { adrenalectomy }\end{array}$ \\
\hline & $\mathrm{meq} / \mathrm{kg}$ & g/day & meq/day & $g$ & $g$ & $\%$ \\
\hline 1 & $(100)$ & $23.3 \pm 3.2(3)$ & $2.3 \pm 0.3(3)$ & $1,250 \pm 79(6)$ & $4.8 \pm 0.3(6)$ & 63.3 \\
\hline 2 & Normal $\quad(300)$ & 21.0 & $6.3 \quad(1)$ & $1,243 \pm 79(5)$ & $5.6 \pm 0.4(5)$ & 42.8 \\
\hline 3 & $(500)$ & $28.4 \pm 4.6(5)$ & $14.2 \pm 2.3(5)$ & $1,322 \pm 68(5)$ & $5.0 \pm 0.4(5)$ & 53.8 \\
\hline 4 & Very high (700) & $22.6 \pm 3.9$ & $15.8 \pm 2.7(5)$ & $1,383 \pm 37(5)$ & $5.4 \pm 0.3(5)$ & 35.8 \\
\hline
\end{tabular}

The values represent mean \pm standard error of the mean of the number of animals given in parenthesis. The body and kidney weights were taken on the day of sacrifice.

the assay is based on hydrolysis of ATP to ADP, which is coupled to oxidation of NADH as follows:

ATP $\frac{\mathrm{Na}^{+}, \mathrm{NH}_{4}^{+}, \mathrm{Mg}^{++}}{\text {ATPase }}$ ADP $+\mathrm{P}_{\mathrm{i}}$
ADP + phosphoenolpyruvate $\frac{\mathrm{NH}_{4}^{+}, \mathrm{Mg}^{++}}{\text {pyruvate kinase }}$ ATP + pyruvate

Pyruvate + NADH $\frac{\text { lactate }}{\text { dehydrogenase }}$ NAD + lactate.

All three reactions were performed in the same vial which was incubated in a shaking water bath at $37^{\circ} \mathrm{C}$ for $30 \mathrm{~min}$. The final composition of the incubation buffer was: $\mathrm{NaCl}, 100 \mathrm{mM} ; \mathrm{NH}_{4} \mathrm{Cl}, 66.7 \mathrm{mM}$; imidazole, $50.3 \mathrm{mM} ; \mathrm{MgCl}_{2}, 3.7 \mathrm{mM}$; EDTA, $0.08 \mathrm{mM} ; \mathrm{Na}_{2} \mathrm{ATP}, 1.1 \mathrm{mM}$; phosphoenolpyruvate, $0.6 \mathrm{mM}$; NADH, $0.017 \mathrm{mM}$; pyruvate kinase, $3.1 \mathrm{U} /$ $\mathrm{ml}$ and lactate dehydrogenase, $4.1 \mathrm{U} / \mathrm{ml}$. The ouabain when present was $1.0 \mathrm{mM}$. Because all the reactants were in considerable excess, the only rate-limited step was generation of ADP from ATP by renal tubular ATPase.

The depletion of NADH was measured fluorometrically. Because there is a linear relationship between ADP formation and NADH oxidation, the ATPase activity was calculated as formation of ADP in picomoles/minute per millimeter. Total ATPase activity (in the absence of ouabain) and the residual ATPase activity (in the presence of ouabain) were determined in triplicate (three segments of the same type). The calculated difference between total ATPase activity and residual $\mathrm{Mg}$ ATPase activity is called Na-K-ATPase activity.

Statistical analysis. Simultaneous comparisons of different parameters of various treatment (dietary $\mathrm{K}^{+}$) groups were made by analysis of variance. Because of the reasons stated by Glantz (11) and Wallenstein et al. (12), we used Bonferroni's method for making individual contrasts between treatment pairs. The null hypothesis was rejected at the 0.05 level of significance. The relationship between the $\mathrm{K}^{+}$excretion and $\mathrm{Na}$ K-ATPase activity was determined by the regression analysis with and without (In) transformation of the data.

\section{Results}

Food intake, animal, and kidney weights (Table I). Because of technical problems, the food intake was recorded in only 14 of 21 experimental animals. There was no apparent difference in the food intake among the four groups of animals. Dietary intake of $\mathrm{K}^{+}$in group 4 was, therefore, about seven times that of group 1 .

There was no significant difference in the final body weights or the kidney weights in the four groups. The survival rate of the adx rabbits varied from $35.8 \%$ (group 4) to $63.3 \%$ (group 1).

Plasma and urine electrolytes (Table II). There was no significant difference in plasma $\mathrm{Na}^{+}$concentration among the four treatment groups. However, the mean plasma $\mathrm{K}^{+}$of group 4 $(6.1 \pm 0.4 \mathrm{meq} / \mathrm{liter})$ was significantly greater than in group 1 $(4.6 \pm 0.3 \mathrm{meq} / \mathrm{liter})$. Aldosterone levels were not detectable $(<2$ $\mathrm{ng} / \mathrm{dl}$ ) in the plasma of any of the animals.

There was no significant difference in $\mathrm{Na}^{+}$excretion among the four groups of animals. However, the rate of $\mathrm{K}^{+}$excretion was significantly greater in animals fed a normal or high- $\mathrm{K}^{+}$diet (groups 2-4) when compared with animals on a low- $\mathrm{K}^{+}$diet (group 1). Because there was no significant difference in the creatinine clearance of the four groups of animals, the greater rate of $\mathrm{K}^{+}$excretion in animals on a high- $\mathrm{K}^{+}$diet was probably due to an increased secretion of $\mathrm{K}^{+}$in these animals. In fact, the fractional excretion of $\mathrm{K}^{+}$in group 4 was $129.5 \pm 24.2 \%$ indicating net $\mathrm{K}^{+}$secretion.

Na-K-ATPase (Table III). Na-K-ATPase activity in the CCD of groups 3 and 4 was significantly greater than in group 1 . The enzyme activity in group 4 was also significantly greater than in group 2. Na-K-ATPase activity in the CNT of group 4 was significantly greater than values obtained in group 1 . However, there were no significant differences in Na-K-ATPase activities in the DCT or MCD among the four treatment groups.

Table II. Plasma and Urine Electrolytes

\begin{tabular}{|c|c|c|c|c|c|c|c|c|}
\hline $\begin{array}{l}\text { Treatment } \\
\text { group }\end{array}$ & & $\mathrm{Na}^{+}$ & $\mathrm{K}^{+}$ & $\begin{array}{l}\text { Plasma } \\
\text { aldosterone }\end{array}$ & $\mathrm{Na}^{+}$excretion & $\mathbf{K}^{+}$excretion & $\begin{array}{l}\text { Creatinine } \\
\text { clearance }\end{array}$ & $\begin{array}{l}\text { Fractional } \\
\text { excretion of } K\end{array}$ \\
\hline & $n$ & meq/liter & meq/liter & & $\mu e q / h$ per $100 \mathrm{~g}$ & ueq/h per $100 \mathrm{~g}$ & $\mathrm{ml} / \mathrm{h}$ & $\%$ \\
\hline 1 & 6 & $139 \pm 4$ & $4.6 \pm 0.3$ & ND & $64 \pm 8$ & $6.7 \pm 0.7$ & $114 \pm 17$ & $17.3 \pm 2.1$ \\
\hline 2 & 5 & $137 \pm 3$ & $5.4 \pm 0.3$ & ND & $60 \pm 20$ & $25.4^{*} \pm 7.4$ & $101 \pm 26$ & $59.2^{*} \pm 10.2$ \\
\hline 3 & 5 & $140 \pm 2$ & $5.1 \pm 0.3$ & ND & $46 \pm 10$ & $32.5^{*} \pm 8.1$ & $138 \pm 25$ & $63.6^{*} \pm 13.2$ \\
\hline 4 & 5 & $140 \pm 4$ & $6.1^{*} \pm 0.4$ & ND & $73 \pm 21$ & $51.8^{*} \pm 8.1$ & $107 \pm 23$ & $129.5 \ddagger \pm 24.2$ \\
\hline
\end{tabular}

Each value represents the mean \pm standard error of the mean of $n$ animals. $\mathrm{ND}$, nondetectable $(<2 \mathrm{ng} / \mathrm{dl}) .{ }^{*} P<0.05$ vs. group $1 . \quad \ddagger P<0.05$ vs. groups 1 and 2. 
Table III. Na-K-ATPase Activity in Rabbit Nephron Segments

\begin{tabular}{llllll}
\hline Treatment group & & DCT & CNT & CCD & MCD \\
\hline & $n$ & $p m o l \cdot \mathrm{min}^{-1} \cdot \mathrm{mm}^{-1}$ & $p \mathrm{~mol} \cdot \mathrm{min}^{-1} \cdot \mathrm{mm}^{-1}$ & $\mathrm{pmol} \cdot \mathrm{min}^{-1} \cdot \mathrm{mm}^{-1}$ & $\mathrm{pmol} \cdot \mathrm{min}^{-1} \cdot \mathrm{mm}^{-1}$ \\
1 & 6 & $76.7 \pm 11.4$ & $43.8 \pm 6.2$ & $9.5 \pm 1.2$ & $10.7 \pm 2.2$ \\
2 & 5 & $62.6 \pm 4.9$ & $66.6 \pm 13.1$ & $16.0 \pm 3.7$ & $16.8 \pm 3.5$ \\
3 & 5 & $69.0 \pm 4.6$ & $68.8 \pm 8.3$ & $23.8 * \pm 0.9$ & $12.2 \pm 1.2$ \\
4 & 5 & $95.0 \pm 12.1$ & $68.6 * \pm 5.5$ & $31.0 \pm \pm 2.8$ & $10.4 \pm 1.1$ \\
\hline
\end{tabular}

Each value represents the mean \pm standard error of the mean of $n$ animals. $* P<0.05$ vs. group $1 . \quad \ngtr<0.05$ vs. group 1 and 2 .

Relationship between $\mathrm{Na}-\mathrm{K}$-ATPase activity and $\mathrm{K}^{+}$excretion (Fig. 1). There was a linear relationship between Na-K-ATPase activity in the $\mathrm{CCD}$ and $\mathrm{K}^{+}$excretion $(y=13.0 \pm 0.24$ and $r$ $=0.53$ ) of all animals. The correlation coefficient was improved $(r=0.67)$ when the data were analyzed after $(\ln )$ transformations. The slope of the regression lines was significantly different from 0 both with and without transformations. There was no significant relationship between $\mathrm{Na}-\mathrm{K}$-ATPase activities in the other three segments (DCT, CNT, and MCD) and $\mathrm{K}^{+}$excretion.

$M g$-ATPase (Table IV). There were no significant differences in Mg-ATPase activities in any of the four types of nephron segments among the treatment groups. The high standard error and mean value in the CNT of group 4 is due to an unusually high Mg-ATPase activity in one of the five rabbits in this group.

\section{Discussion}

Dietary $\mathrm{K}^{+}$and renal $\mathrm{Na}-\mathrm{K}$-ATPase activity. Our results demonstrate for the first time that Na-K-ATPase activity in CCD and CNT of adx rabbits can be modulated by dietary $\mathrm{K}^{+}$. The potassium load in the diet has been shown previously to increase renal Na-K-ATPase activity in non-adx (intact) animals (1) where changes in the enzyme activity have been localized mainly to the $\operatorname{CCD}(4,5)$. However, an increase in the plasma $\mathrm{K}^{+}$concentration also increases the secretion of aldosterone $(7,8)$, which

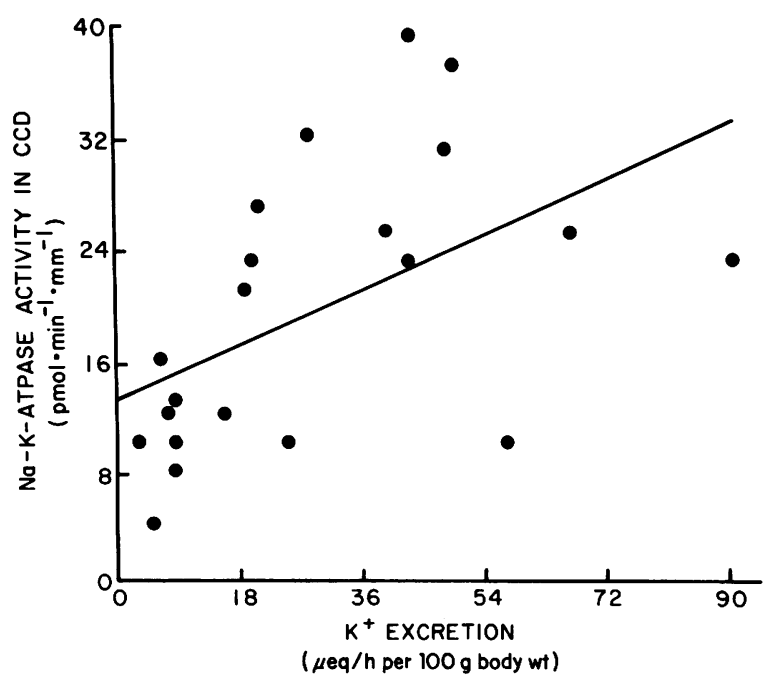

Figure 1. Relationship between Na-K-ATPase activity in the CCD and $\mathrm{K}^{+}$excretion. The regression equation for this relationship is: $y=13.0$ $+0.24 x$ with a correlation coefficient $(r)$ of 0.53 . The slope of the regression line is significantly different from zero at $P<0.05$. is a strong stimulus for increasing Na-K-ATPase activity in the $\operatorname{CCD}(6,13,14)$. In the present study we have demonstrated that Na-K-ATPase activity in the CCD and CNT can also be increased by increasing the dietary $\mathrm{K}^{+}$intake in the absence of aldosterone. These results are consistent with those of Silva et al. (1), who demonstrated that $\mathrm{K}^{+}$loading increased $\mathrm{Na}-\mathrm{K}$ ATPase activity in renal cortical homogenates from adx rats maintained on a fixed dose of deoxycorticosterone. Our results are also consistent with those of Doucet and Katz (4), who reported that $\mathrm{K}^{+}$loading in intact mice increased Na-K-ATPase activity in the CCD even after treatment with spironolactone (an aldosterone antagonist). However, our results are at variance with those of Mujais et al. (15), who reported that the Na-KATPase activity in the CCD of adx rats was not increased by an increase in dietary $\mathrm{K}^{+}$intake. The reasons for the differences between our results and those of Mujais et al. (15) are not readily apparent except for the species difference of the two animal models studied.

Silva et al. (1) reported that $\mathrm{K}^{+}$loading in intact rats also increased Na-K-ATPase activity in the renal medulla. Doucet and Katz (4) reported a $20 \%$ and $200 \%$ increase in Na-K-ATPase activity in the medullary thick ascending limb and the MCD, respectively, after increasing dietary $\mathrm{K}^{+}$in intact mice. However, in an earlier study, we did not find a decrease in Na-K-ATPase activity in the MCD after decreasing dietary $\mathrm{K}^{+}$in the intact rat (5). In the present study, we did not determine Na-K-ATPase activity in the medullary thick ascending limb. Furthermore, we did not find a significant change in Na-K-ATPase activity in the MCD of adx rabbits after changing the dietary $\mathrm{K}^{+}$content of the animals. Our results are consistent with those of Stokes (16), who did not find any evidence of active secretion of $\mathrm{K}^{+}$in the MCD. However, the role of Na-K-ATPase in $\mathrm{K}^{+}$adaptation in the medullary segments needs to be examined further in both the presence and the absence of aldosterone.

Potassium excretion. In the present studies changes in $\mathrm{Na}$ $\mathrm{K}$-ATPase activity in the CNT and the CCD were accompanied by changes in $\mathrm{K}^{+}$excretion in adx animals. Potassium excretion increased four- to sevenfold in adx animals fed high- $\mathrm{K}^{+}$diets (groups 2, 3, and 4 in Table II). The fractional excretion of $\mathrm{K}^{+}$ in animals on very high- $\mathrm{K}^{+}$diet (group 4 ) was $130 \%$ compared to just $17 \%$ in animals on low-K $\mathrm{K}^{+}$diet (group 1 ). These results demonstrate that inspite of adrenalectomy, there was net secretion ( $>100 \%$ excretion) of $\mathrm{K}^{+}$in animals ingesting a diet very high in $\mathrm{K}^{+}$, and there was net reabsorption $(<100 \%$ excretion) of $\mathrm{K}^{+}$in animals on a low- $\mathrm{K}^{+}$diet. Previously, it has been shown that intact animals adapt to increased $\mathrm{K}^{+}$load by excreting more $\mathrm{K}^{+}(2,17,18)$. This has been attributed to an increase in the plasma aldosterone level $(7,8,18,19)$. Our results demonstrate that $\mathrm{K}^{+}$excretion can be increased in adx rabbits in response to 
Table IV. Mg-ATPase Activity in Rabbit Nephron Segments

\begin{tabular}{llllll}
\hline Treatment group & & DCT & CNT & CCD & MCD \\
\hline & $n$ & $p m o l \cdot \mathrm{min}^{-1} \cdot \mathrm{mm}^{-1}$ & $\mathrm{pmol} \cdot \mathrm{min}^{-1} \cdot \mathrm{mm}^{-1}$ & $\mathrm{pmol} \cdot \mathrm{min}^{-1} \cdot \mathrm{mm}^{-1}$ & $\mathrm{pmol} \cdot \mathrm{min}^{-1} \cdot \mathrm{mm}^{-1}$ \\
1 & 6 & $49.3 \pm 6.9$ & $37.3 \pm 8.1$ & $14.0 \pm 2.9$ & $12.3 \pm 2.5$ \\
2 & 5 & $34.2 \pm 2.4$ & $37.6 \pm 4.3$ & $17.8 \pm 6.4$ & $19.6 \pm 5.0$ \\
3 & 5 & $40.8 \pm 5.5$ & $45.0 \pm 9.5$ & $15.2 \pm 1.7$ & $8.4 \pm 1.6$ \\
4 & 5 & $45.6 \pm 5.0$ & $62.0 \pm 20.5$ & $13.8 \pm 2.9$ & $7.0 \pm 2.6$ \\
\hline
\end{tabular}

Each value represents the mean \pm standard error of the mean of $n$ animals.

an increased intake of dietary $\mathrm{K}^{+}$in the absence of aldosterone. These results, together with those reported by other investigators, suggest that the increased renal excretion of $\mathrm{K}^{+}$that occurs in response to a $\mathrm{K}^{+}$load is the result of two processes: an aldosterone-dependent process and an aldosterone-independent process. The relative importance of each can not be ascertained from the present data.

Mechanism of $\mathrm{K}^{+}$adaptation. The adaptive changes in $\mathrm{Na}-$ $\mathrm{K}$-ATPase in the CCD of the adx rabbit produced by dietary $\mathrm{K}^{+}$were preserved in vitro even after killing the animals. It seems likely that in this experimental setting the changes in Na-KATPase activity may be due to a change in the number of active enzyme units as has been shown in the case of intact animals (20) rather than result from a change in enzyme kinetics. The mechanism whereby the increase in dietary $\mathrm{K}^{+}$intake would result in an increase in Na-K-ATPase activity cannot be delineated from the present studies. It is possible that $\mathrm{K}^{+}$not only regulates the kinetics of the $\mathrm{Na}^{+}$pump (21), but may also regulate steady-state levels of Na-K-ATPase either by affecting the rate of synthesis or by modifying the rate of its degradation. On the other hand, it is possible that $\mathrm{K}^{+}$may release or suppress some nonadrenal hormone (or factor) that may modulate $\mathrm{Na}-\mathrm{K}$ ATPase activity in CCD and CNT of adx animals. It is also likely that changes in Na-K-ATPase activity in the CNT and the $\mathrm{CCD}$ in adx rabbits are the result of changes in $\mathrm{K}^{+}$recycling produced by dietary $\mathrm{K}^{+}$. The concept of $\mathrm{K}^{+}$recycling as proposed by Jamison et al. (22) involves net secretion of $\mathrm{K}^{+}$in the CNT and the $\mathrm{CCD}$. The secreted $\mathrm{K}^{+}$is concentrated in the $\mathrm{CCD}$ by water abstraction. Because of a favorable electrochemical gradient, the $\mathrm{K}^{+}$is reabsorbed in the MCD. The reabsorbed $\mathrm{K}^{+}$is secreted into the pars recta and the thin descending limb to produce a high $\mathrm{K}^{+}$concentration at the bend of the loop of Henle of juxtamedullary nephrons. Chronic $\mathrm{K}^{+}$loading in the intact rat has been shown to increase $\mathrm{K}^{+}$delivery at the bend from $100 \%$ to $300 \%$ of the filtered load (22). Recently, the increased $\mathrm{K}^{+}$concentration has been demonstrated to decrease $\mathrm{NaCl}$ reabsorption in the medullary thick ascending limb (23). This process would increase the delivery of salt and water to distal segments resulting in an increased secretion of $\mathrm{K}^{+}$in the $\mathrm{CNT}$ and the CCD. If these events occur in the adx rabbit, the increase in Na-K-ATPase activity in the CNT and the CCD in the present study may be due to an increase in $\mathrm{K}^{+}$recycling after $\mathrm{K}^{+}$loading of animals.

The results obtained by several investigators $(24,25)$ using in vitro perfusion of the CCD support a model in which transepithelial secretion of $\mathrm{K}^{+}$is driven by Na-K-ATPase in the basolateral membrane and moves passively through a $\mathrm{K}^{+}$-conductive pathway in the apical membrane. Secretion of $\mathrm{K}^{+}$in the CCD is related to $\mathrm{Na}^{+}$reabsorption which is dependent on its entry into the renal tubular cells through the apical membrane. Although apical $\mathrm{Na}^{+}$permeability in the CCD is influenced by mineralocorticoids, Wingo et al. (26) reported that $\mathrm{K}^{+}$secretion in the CCD can be increased by increasing dietary $\mathrm{K}^{+}$independently of mineralocorticoids. Furthermore, Wingo (27) has shown that $\mathrm{K}^{+}$secretion in the CCD of adx rabbits can be inhibited completely by ouabain, thus indicating that $\mathrm{K}^{+}$secretion in this segment is dependent on Na-K-ATPase even in the absence of mineralocorticoids. Our data are the first to provide measurements of Na-K-ATPase activity in the CCD and other distal segments of adx animals fed different $\mathrm{K}^{+}$diets. We have demonstrated a substantial $(>200 \%)$ increase in Na-K-ATPase activity in the CCD of adx animals given a very high- $\mathrm{K}^{+}$diet (Fig. 2). The dietary $\mathrm{K}^{+}$produced a somewhat smaller increase in Na-K-ATPase activity in the CNT of the adx rabbits. Our results suggest that $\mathrm{CCD}$ and $\mathrm{CNT}$ are important sites of handling $\mathrm{K}^{+}$in adx animals as is true in intact animals (2-5). Furthermore, our data suggest that in these segments $\mathrm{Na}-\mathrm{K}-\mathrm{ATPase}$ is involved in $\mathrm{K}^{+}$adaptation regardless of the mineralocorticoid status of the animals. Thus, our data are consistent with a model of $\mathrm{K}^{+}$ secretion that involves Na-K-ATPase in the basolateral membrane and passive $\mathrm{K}^{+}$movement in the apical membrane of the $\operatorname{CCD}(24,25)$ irrespective of the mineralocorticoid status of the animal.

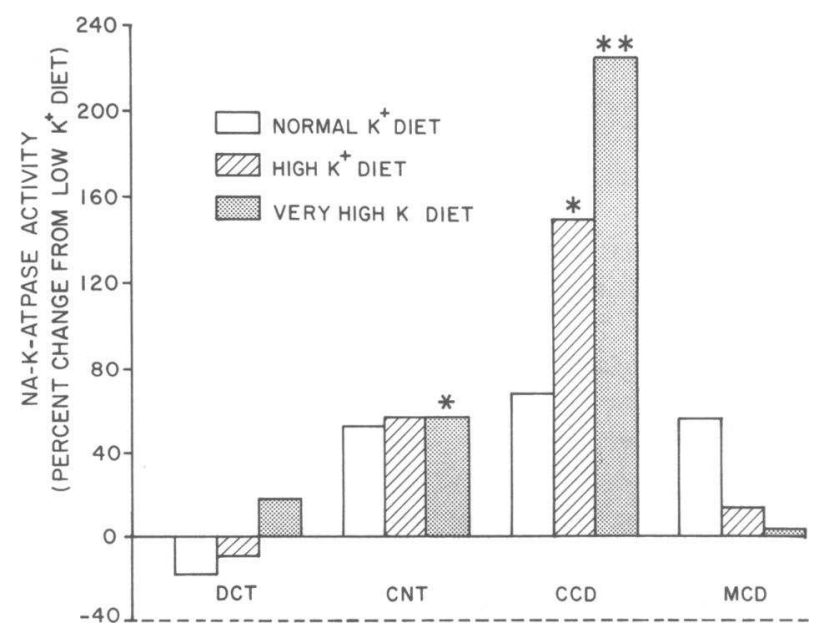

Figure 2. Na-K-ATPase activity in distal nephron segments of adx rabbits given different $\mathrm{K}^{+}$diets. Results are expressed as percent change in the enzyme activity in nephron segments of rabbits given low $\mathrm{K}^{+}$diet. Abbreviations used for nephron segments are explained in the text. ${ }^{*} P<0.05$ vs. low- $\mathrm{K}^{+}$diet group; ${ }^{* *} P<0.05$ vs. low- $\mathrm{K}^{+}$ and normal- $\mathrm{K}^{+}$diet groups. 
Adaptation to a dietary $\mathrm{K}^{+}$load also involves certain extrarenal mechanisms such as the secretion of $\mathrm{K}^{+}$into the colon (28-30). These processes are probably dependent on aldosteronestimulated Na-K-ATPase in the colonic mucosa. Recently, Martin et al. (31) reported that the administration of a high- $\mathrm{K}^{+}$ diet to adx rats did not increase $\mathrm{K}^{+}$secretion into the colon. These results are not necessarily inconsistent with our present data for the following reason. If adaptation to moderate loads of $\mathrm{K}^{+}$does occur in adrenal insufficiency in animals as in humans $(32,33)$, it may occur through the Na-K-ATPase-dependent renal secretion of $\mathrm{K}^{+}$rather than both renal and colonic secretion of this ion.

Adrenal steroids and dietary $\mathrm{K}^{+}$. The relative importance of dietary $\mathrm{K}^{+}$and adrenal steroids in modulating Na-K-ATPase activity in the CCD (and CNT) and $\mathrm{K}^{+}$adaptation cannot be determined from the available data. Bilateral adrenalectomy has been shown to decrease renal Na-K-ATPase activity by $\sim 40 \%$ (21). In the present study, Na-K-ATPase activity in four different distal nephron segments from adx rabbits was $40-60 \%$ less when compared with values for Na-K-ATPase activity in the same segments obtained from intact rabbits as reported previously (6). Petty et al. (13) and El Mernissi and Doucet (14) reported a $40-85 \%$ decrease in the Na-K-ATPase activity in the DCT and the $\mathrm{CCD}$ of adx rabbits. The quantitative differences in the decrease of Na-K-ATPase activity in the CCD after adrenalectomy in various studies may be due to a difference in food $\left(\mathrm{K}^{+}\right)$ intake of adx animals. However, it should be pointed out that, in our studies and in those of Petty et al. (13) and El Mernissi and Doucet (14), Na-K-ATPase activity in the distal segments of adx rabbits was significantly greater than zero. This suggests that if $\mathrm{K}^{+}$secretion into the distal tubular segments is dependent on Na-K-ATPase activity, $\mathrm{K}^{+}$secretion should occur at a significant rate even in adx animals. As discussed above, this has been shown to be true in the $\operatorname{CCD}(26,27)$.

The rate of decline in whole kidney Na-K-ATPase activity after adrenalectomy has been shown to depend on $\mathrm{Na}^{+}$intake and the plasma $\mathrm{Na}^{+}$concentration (21). In the present study the $\mathrm{Na}^{+}$content in the diets and in the drinking water of all four groups of animals was the same. Furthermore, there was no significant difference in the plasma $\mathrm{Na}^{+}$concentration, the creatinine clearance, or the rate of $\mathrm{Na}^{+}$excretion (Table II) in the four groups. Therefore, the differences in Na-K-ATPase activity in CCD and CNT (Fig. 2) in the four groups of adx animals in the present study cannot be explained by differences in the filtered load of $\mathrm{Na}^{+}$.

An increase of $200 \%$ in Na-K-ATPase activity in the CCD by the dietary $\mathrm{K}^{+}$in adx rabbits in the present study (Fig. 2) was of the same magnitude as was obtained by hyperaldosteronism produced in intact rabbits by feeding a low-sodium diet (6). Because the food and $\mathrm{K}^{+}$intake may also differ in adx and intact animals, further studies are needed to determine the relative importance of the effects of dietary $\mathrm{K}^{+}$and hyperaldosteronism on Na-K-ATPase activity and whether they have an additive effect in the CCD and the CNT.

In summary, these experiments performed on adx rabbits demonstrate that potassium loading causes an increase in Na$\mathrm{K}-\mathrm{ATPase}$ activity in the CNT and the CCD. The increase in renal tubular $\mathrm{Na}-\mathrm{K}$-ATPase activity in association with potassium loading is not dependent on a priming action of adrenal steroids. Our data may explain a mechanism by which tolerance to moderate $\mathrm{K}^{+}$loads develops in patients with uncomplicated adrenal insufficiency maintained on a high salt intake $(32,33)$.

\section{Acknowledgments}

We thank Ms. Sheryl Nash for technical assistance, Drs. Charles S. Wingo and Allen H. Neims for useful discussions, and Dr. C. Craig Tisher for reviewing the manuscript.

This work was supported by a grant from the National Science Foundation (DCB-8213821).

\section{References}

1. Silva, P., J. P. Hayslett, and F. H. Epstein. 1973. The role of NaK-activated adenosine triphosphatase in potassium adaptation: stimulation of enzymatic activity by potassium loading. J. Clin. Invest. 52: 2665-2671.

2. Wright, F. S. 1977. Sites and mechanism of potassium transport along the renal tubule. Kidney Int. 11:415-432.

3. Stanton, B. A., D. Biemesderfer, J. B. Wade, and G. Giebisch. 1981. Structural and functional study of the rat distal nephron: effects of potassium adaptation and depletion. Kidney Int. 19:36-48.

4. Doucet, A., and A. I. Katz. 1980. Renal potassium adaptation: Na-K-ATPase activity along the nephron after chronic potassium adaptation. Am. J. Physiol. 238:F380-F386.

5. Garg, L. C., S. Mackie, and C. C. Tisher. 1982. Effect of low potassium diet on Na-K-ATPase in rat nephron segments. Pflügers Arch. Eur. J. Physiol. 394:113-117.

6. Garg, L. C., M. A. Knepper, and M. B. Burg. 1981. Mineralocorticoid effects on Na-K-ATPase in individual nephron segments. Am. J. Physiol. 240:F536-F544.

7. Boyd, J. E., W. P. Palmore, and P. J. Murlow. 1971. Role of potassium in the control of aldosterone secretion in the rat. Endocrinology. 88:556-565.

8. Boyd, J. E., W. P. Palmore, and P. J. Murlow. 1972. Further studies on the influence of potassium upon aldosterone production in the rat. Endocrinology. 90:299-301.

9. Arrington, L. R. 1972. Breeding, care and management of experimental animals. In Introductory Laboratory Animal Science. Interstate Printing and Publishing, Inc., Danville, IL. 82.

10. Garg, L. C. 1975. The absence of renal bicarbonate reabsorption maxima during carbonic anhydrase inhibition. J. Pharmacol. Exp. Ther. 194:96-102.

11. Glantz, S. A. 1980. Biostatistics: how to detect, correct and prevent errors in the medical literature. Circulation. 61:1-7.

12. Wallenstein, S., C. L. Zucker, and J. L. Fleiss. 1980. Some statistical methods useful in circulation research. Circ. Res. 47:1-9.

13. Petty, K. J., J. P. Kokko, and D. Marver. 1981. Secondary effect of aldosterone on Na-K-ATPase activity in the rabbit cortical collecting tubule. J. Clin. Invest. 68:1514-1521.

14. El Mernissi, and A. Doucet. 1983. Short term effects of aldosterone and dexamethasone on Na-K-ATPase along the rabbit nephron. Pflügers Arch. Eur. J. Physiol. 399:147-151.

15. Mujais, S. K., M. A. Chekal, W. J. Jones, J. P. Hayslett, and A. I. Katz. 1984. Aldosterone mediates the increase in renal Na-K-ATPase in potassium adaptation. Ninth International Congress of Nephrology. 457a. (Abstr.)

16. Stokes, J. B. 1982. Na and $K$ transport across the cortical and outer medullary collecting tubule of the rabbit: evidence for diffusion across the outer medullary portion. Am. J. Physiol. 242:F514-F520.

17. Thatcher, J. S., and A. W. Radke. 1947. Tolerance to potassium intoxication in the albino rat. Am. J. Physiol. 151:138-146.

18. Giebisch, G. 1979. Renal potassium transport. In Membrane Transport in Biology. G. Giebisch, D. C. Tosteson, and H. H. Ussing, editors. Springer-Verlag, Inc., New York. 4B:215-298.

19. Hierholzer, K., and S. Lange. 1975. The effects of adrenal steroids on renal function. In Medical and Technical Publishing Co. International Review of Science: Kidney and Urinary Tract Physiology. K. Thurau, editor. Butterworths, London. 273-334.

20. Rodriguez, H. J., W. C. Hogan, R. N. Hellman, and S. Klahr. 
1980. Mechanism of activation of renal Na-K-ATPase in the rat: effects of potassium loading. Am. J. Physiol. 238:F315-F323.

21. Jorgensen, P. L. 1968. Regulation of $\mathrm{Na}^{+}+\mathrm{K}^{+}$-activated ATP hydrolyzing system in the rat kidney. I. The effect of adrenalectomy and the supply of sodium on the enzyme system. Biochim. Biophys. Acta. 151:212-224.

22. Jamison, R. L., J. Work, and J. A. Schaffer. 1982. New pathways for potassium transport in the kidney. Am. J. Physiol. 242:F297-F312.

23. Stokes, J. B. 1982. Consequences of potassium recycling in the renal medulla. J. Clin. Invest. 70:219-229.

24. Stokes, J. B. 1981. Potassium secretion by cortical collecting tubule: relation to sodium reabsorption, luminal sodium concentration and transepithelial voltage. Am. J. Physiol. 241:F395-F402.

25. Koeppen, B. M., B. A. Biagi, and G. Giebisch. 1983. Intracellular microelectrode characterization of the rabbit cortical collecting duct. Am. J. Physiol. 244:F35-F47.

26. Wingo, C. S., S. W. Seldin, J. P. Kokko, and H. R. Jacobsen. 1982. Dietary modulation of active potassium secretion in the cortical collecting tubule of adrenalectomized rabbits. J. Clin. Invest. 70:579586.
27. Wingo, C. S. 1984 . Effect of ouabain on $\mathrm{K}^{+}$secretion in cortical collecting tubules from adrenalectomized rabbits. Am. J. Physiol. 247: F588-F595.

28. Alexander, E. A., and N. G. Levinsky. 1968. An extrarenal mechanism for the maintenance of potassium adaptation. J. Clin. Invest. 44: 740-748.

29. Hayslett, J. P., and H. J. Binder. 1982. Mechanism of potassium adáptation. Am. J. Physiol. 243:F103-F112.

30. Bia, M. J., and R. A. DeFronzo. 1981. Extra-renal potassium homeostasis. Am. J. Physiol. 240:F257-F268.

31. Martin, R. S., P. Oszi, S. Brocca, and E. Arrizurieta. 1984. Failure of $\mathrm{K}^{+}$adaptation in the colon of aldosterone (A) deficient rats. Ninth International Congress of Nephrology. 455a. (Abstr.)

32. Fawley, F. F. 1967. Adrenal cortical insufficiency. In The Adrenal Cortex. A. B. Einstein, editor. Churchill Ltd., London. 439-522.

33. Talbot, J. H., L. J. Pecora, R. S. Melville, and W. V. Cansolayio. 1942. Renal function in patients with Addison's disease and in patients with adrenal insufficiency secondary to pituitary-pan-hypofunction. $J$. Clin. Invest. 21:107-119. 